\title{
The Employment Effect of Stricter Rules for Eligibility for DI: Evidence from a Natural Experiment in Sweden*
}

\author{
Anders Karlström, Mårten Palme ${ }^{\ddagger}$ and Ingemar Svensson ${ }^{\S}$
}

April 11, 2008

\begin{abstract}
We study the effect of a reform of the Swedish disability insurance (DI) program whereby the special eligibility rules for workers in the age group 60 to 64 were abolished. First, we use a differences-in-differences approach to study changes in the disability take-up as compared to the age group 55 to 59 . Then, we use a similar approach to study to what extent the employment effect of the reform is "crowded out" by an increase in the utilization of the sickpay insurance (SI) and/or the unemployment insurance (UI). In an extended analysis, we study the effect of firm closure on employment and the utilization of different labor market insurance programs in different age groups before and after the reform.
\end{abstract}

Key words: Disability insurance, Early retirement.

JEL: H53, H55, H59, J21, J26.

*We thank two anonymous referees, participants at the June 2006 TAPES conference in Uppsala, in particular our discussants Axel Börsch-Supan and Marie-Louise Leroux, for constructive comments. We also thank Maria Fröberg for excellent research assistance. Anders Karlström and Mårten Palme acknowledge financial support from the Bank of Sweden Tercentenary Foundation and the Swedish Council for Working Life.

†Systems Analysis and Economics, Royal Institute of Technology, SE-100 44 Stockholm, Sweden. E-mail: andersk@infra.kth.se.

${ }^{\ddagger}$ Department of Economics, Stockholm University, SE-106 91 Stockholm, Sweden. Email: Marten.Palme@ne.su.se.

§Social Insurance Agency, SE-103 51 Stockholm, Sweden. E-mail: Ingemar.Svensson@forsakringskassan.se. 


\section{Introduction}

Like most other industrialized countries, Sweden has experienced a trend towards earlier exit from the labor market since the early 1960s. The most common path of exit before the normal retirement age at 65 is through the Disability Insurance (DI). Between 35 and 40 percent of each birth cohort receive DI and, although the general health status has improved, the share of the population receiving DI has been increasing. Besides a generally higher income level and more generous benefits, one of the main reasons for this development is a gradual transformation of the eligibility rules for DI from a strict application of health reasons in the 1950s to also awarding DI benefits for labor market reasons or a combination of health and labor market reasons. This change can be described as a transformation from a Disability Insurance system to more of an Early Retirement scheme.

In recent years, however, there has been a development towards reversing the DI back to an insurance against loss of income from labor due to permanent health deficiencies. DI eligibility for pure labor market reasons for workers aged between 60 and 64 was abolished in 1991. In a subsequent reform, implemented in 1997, the eligibility for DI for labor market reasons in combination with health reasons as well as the special eligibility rules for the age group 60-64 were abolished. The special rules for workers aged above 60 implied that the medical requirements were lower as were the requirements to change residence or occupation. In addition, these individuals were not required to participate in retraining or rehabilitation programs.

Figures 1 and 2 show the development of labor force participation rates 
since 1963 for five different age groups for males and females, respectively. ${ }^{1}$ There has been a rapid increase in the labor force participation rate in the age group 60-64 since 1997. There may be several possible explanations for this development. In this paper, we study the effect on labor force participation and employment of the 1997 reform. In particular, we study the decrease in the inflow to disability pension and to what extent this decrease is "crowded out" by increases in the utilization of the other main public labor market insurance programs: the sick pay insurance program (SI), which replaces labor earnings due to temporary health problems, and the unemployment insurance (UI). We primarily rely on differences-in-differences as our empirical strategy in that we compare the outcome of the age group affected by the reform - those aged 60-64 - with that of the group aged 55-59. In an extended analysis, we study the effect of firm closure on employment and the utilization of different labor market insurance programs in different age groups before and after the reform.

The paper is organized as follows. Section 2 describes Sweden's income security system and the 1997 reform of eligibility for DI. Section 3 discusses likely effects of the reform on transitions between different states on the labor market, i.e., possible mechanisms for "crowding out". Section 4 presents our data set and provides descriptive statistics. Section 5 describes the empirical strategy and Section 6 presents the results. Finally, Section 7 concludes.

\footnotetext{
${ }^{1}$ Individuals receiving disability insurance are classified as not included in the labor force, while those receiving sickpay or unemployment insurance benefits are.
} 


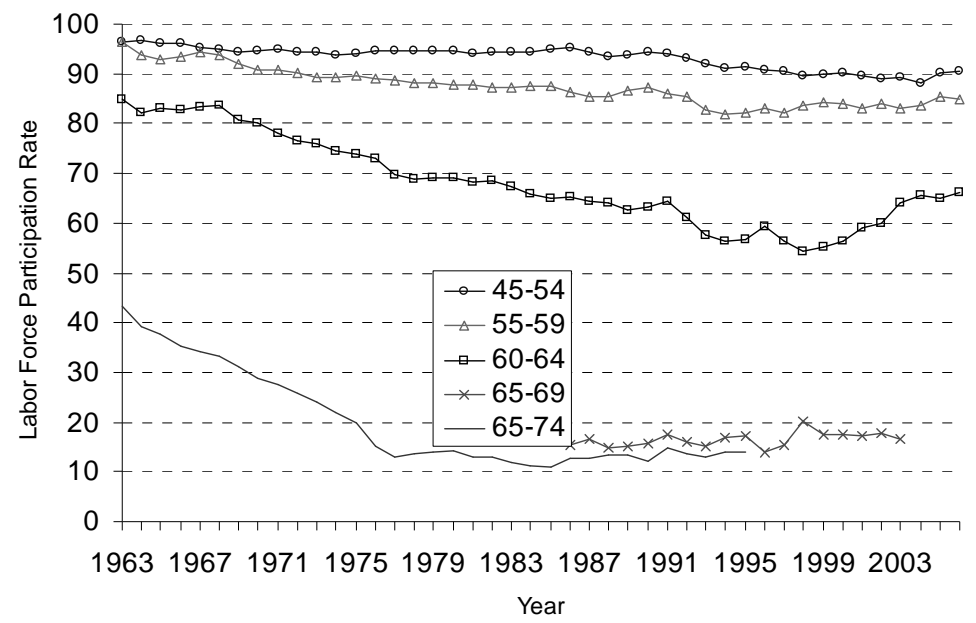

Figure 1: Labor force participation rates in Sweden 1963-2006. Males by different age groups. Source: Various reports of the Swedish Labor Force Survey, provided by Statistics Sweden.

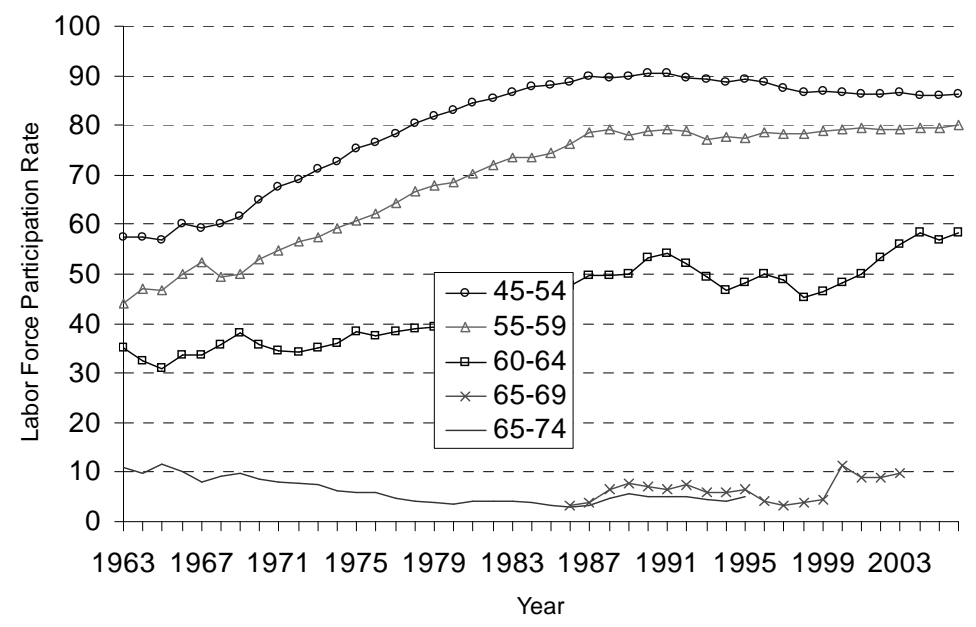

Figure 2: Labor force participation rates in Sweden 1963-2006. Females by different age groups. Source: See Figure 1. 


\section{Sweden's Income Security System and the 1997 Reform of the DI program}

\subsection{Sweden's Income Security System}

The income security system in Sweden consists of two main parts: the oldage pension system and the compulsory labor market insurance programs. Both these parts are, to about the same extent, used for financing exits from the labor market. In this subsection, we give a brief description of how these programs are constructed. ${ }^{2}$ We start with the old-age pension programs. Then, we describe disability, sickness and unemployment insurance programs.

\subsubsection{Old-age Pension Programs}

In 1998, a decision was taken by the Swedish parliament on a new public old-age pension system which is implemented by birth cohort. Those born in 1938 constitute the first cohort to be partially in the new system. These individuals are 20 percent in the new system and 80 percent in the pre-reform system. The share in the new system increases by 5 percentage points for each birth cohort. Pensions according to the new system were paid for the first time in 2001. This means that individuals included in this study are mainly affected by the pre-reform system.

The pre-reform public old-age pension system consisted of two main parts during the period studied: a basic pension and the supplementary pension (ATP). The basic pension is unrelated and the supplementary pension related to the workers' previous earnings. Workers with no, or low, supplementary pension receive a special supplement to the basic pension.

\footnotetext{
${ }^{2}$ For a more complete description, see Palme and Svensson (1999 or 2004).
} 
Both the old and the new pension systems have a normal retirement age of 65 , but the pension can be claimed from the age of 61 . The prereform pension program has a permanent actuarial reduction of 0.5 percent for each month of early withdrawal and a 0.7 percent actuarial increase for each month of delayed withdrawal up to the age of 70 . Both the NDC (Notional Defined Contribution) and the fully funded parts of the new system should be actuarially fair with respect to when the pension is claimed. Very few use the option of exiting from the labor market through early withdrawal from the public pension system. Eklöf and Hallberg (2004) find that 8.5 percent of the males that exit at age 63 and 4.1 of the females who exit at the same age get their main income from the public old-age pension programs.

Sweden has a very unionized labor market. About 95 percent of the labor market are covered by collective agreements which also include occupational pension programs. The benefits from these pension programs correspond to about 10 percent of the forgone earnings for blue-collar workers in the private sector. Occupational pensions are much more important for whitecollar workers, where these replace foregone earnings above the social security ceiling. Eklöf and Hallberg (2004) show that occupational pensions constitute the main income source for 29.4 percent of the male workers who exit at age 63 and 50.1 percent of the female workers who exit at the this age. This means that the occupational pensions are more important as a support program than the public old-age pensions for those leaving the labor force before the age of 65 . 


\subsubsection{Labor Market Insurances}

There are three important labor market insurances: disability insurance (DI), sickness insurance (SI) and unemployment insurance (UI). Eligibility for disability insurance requires that the individual's capacity to work is permanently reduced by at least 25 percent. Full compensation requires that the capacity is completely, or almost completely, lost. Medical conditions pertaining to work capacity are, in general, assessed by several physicians, and eligibility for disability insurance is finally determined by the local social insurance administration. Between 1972 and 1991, disability insurance could be granted for labor market reasons for older workers. Between 1972 and 1974 the age limit was set to 63 and in 1974 it was changed to age 60 .

Until 2003, the disability benefits consisted of a basic pension and a supplementary pension (ATP). The level of the basic pension is the same as for the old-age scheme and the supplementary pension is determined in the same way as for the old-age scheme, with no actuarial reduction for early retirement. "Assumed" pension points are calculated for each year between the date of retirement and the age of 64 . The special supplement for disability pensioners is higher than for old-age pensioners. In 2003, which is beyond the period covered by our analysis, completely new rules for the calculation of benefits were implemented.

Sickness insurance replaces a share of lost earnings due to temporary illnesses up to the social security ceiling. The replacement level in the insurance has been changed on several occasions during the time period covered by this study. In a reform in 1987, the replacement level was set at 90 percent of the worker's insured income. Since then, the replacement has been decreased on 
several occasions. The first time was in a reform in 1991. In 1996, it was set to 75 percent of the insured income for long sickness spells and in 1998, it was raised to 80 percent.

Although the sickpay insurance program aims at insuring income losses from short-term illnesses, very long spells have become more common and the program has become an important pathway for leaving the labor force. At the end of 2006, there were seven sickpay insurance spells longer than two years for every 1,000 insured workers. The legislation requires the social insurance offices to assess the individual's possibilities of returning to work in long sickpay insurance spells. If the loss of work ability is considered to be "not temporary", the individual should be moved to the disability insurance program. There is, however, no formal definition of "temporary" and the application of the law varies, both over time and between social insurance offices. A sickpay insurance spell has no time limit.

The unemployment insurance benefit consists of two parts: one basic part, which is unrelated to the worker's insured income, and one part which requires membership in an unemployment benefit fund and is related to the worker's insured income. Unemployed workers actively searching for a new job are eligible for compensation. The main difference between the benefit level in the unemployment and sickness insurance is the ceiling. The ceiling of the latter is the same as for other parts of the social insurance system, while that of the former is subject to discretionary changes, and is lower than the ceiling for the sickness benefit. The replacement rate for unemployment insurance has also been changed on several occasions during the time period analyzed in this study. These changes have roughly followed the changes in 
the sickness insurance.

\subsection{The 1997 Reform of Eligibility for DI}

Before 1997, the eligibility rules for Disability Insurance allowed for a more generous treatment of workers aged above 60 . The more favorable treatment of the older workers contained three main elements. (a) the medical requirements for assessing inability to work were substantially lower for older workers; (b) there were lower requirements for older workers to change occupations or places of living in order to find a suitable job given the reduction in work ability; and (c) the older workers were not required to participate in retraining or rehabilitation programs.

The right to Disability Insurance for long-term unemployed workers aged above 60 was abolished in 1991. However, items (b) and (c) in the pre-1997 legislation implied that local labor market conditions were explicitly allowed to affect eligibility for Disability Insurance, although eligibility implied that non-trivial health conditions affecting the ability to work had to be fulfilled.

The favorable rules for older workers were abolished for all workers turning 60 before July 1. To benefit from the pre-reform rules, an additional requirement was that the application was filed before January 1, 1997. The reform was announced already in 1995. This means that it was possible for workers who fulfilled the requirement for the pre-reform special rules, who anticipated the changes in the eligibility rules, to apply for Disability Insurance before the 1997 reform was implemented.

The 1997 reform also implied changes applying to all ages. It was clarified that a reduced work capacity must have a medical cause in order to give right 
to a benefit, both for disability and sickpay insurance. Work capacity should also be judged in relation to all jobs "normally available on the labor market", not just jobs in the current occupation or region. The social insurance offices should decide on work capacity and eligibility in a standardized procedure taking work capacity first with the current employer and subsequently the entire labor market into account.

\section{Possible Effects of the Reform of DI El- igibility on Transitions between Different Labor Market States}

Figure 3 illustrates the transition from employment into each of the four main income security programs in Sweden: the Unemployment Insurance (UI), the Sickness Insurance (SI), the Disability Insurance (DI) and the possibility of getting old age pension before the normal retirement age of 65 (Early Retirement, ER). We define two states in addition to the states considered in Figure 3 as "Combination" and "Other". Then, it is possible to study the transition probabilities between each of these states as well as the probability of remaining in the same state between two consecutive years. We classify DI and ER as absorbing states, since a very small number of workers return to the labor force after they have started to claim either DI or ER benefits. There are also very small flows between DI and ER.

A change in the eligibility rules for the Disability Insurance has a direct effect on the transition probabilities between work and DI, the transition marked with 4 in Figure 3, as well as between each of the two other labor market insurance programs, Sickpay Insurance, Unemployment Insurance, 
i.e. the transitions marked 10 and 12 , respectively. The change in the eligibility rules may, however, also generate several indirect effects in the transitions between states considered in Figure 3. The most obvious ones are the transitions from work to the Sickpay or Unemployment Insurance programs: if a worker is no longer eligible for DI for labor market reasons or as a result of the favorable rules for older workers, he or she may instead try to be eligible for the other two labor market insurance programs.

In addition to an effect on each of the transitions marked with arrows in Figure 3, it may also affect the persistence in each of the states considered. For example, since eligibility for DI for older workers was abolished in the reform, the transition between UI and DI may be affected and, as a result, also the persistence in UI.

We focus on the two overall effects of the reform: the transition from employment into different income security programs (the sum of the arrow marked by 1,3,4 and 6 in Figure 3) and the persistence in non-employment and support from these programs. Together, these two effects make up for the overall effect of the reform on employment. The effect on all other income security programs but DI, is characterized as "crowding out" of the reform effect.

In addition to the overall effect, we study the separate effect on each income security program. First, the effect on UI dependence raises the important question of a reform effect on the unemployment rate (see Autor and Duggan, 2003). Second, a similar effects are expected on SI, since it is also an obvious substitute to DI. Finally, the reform may have had an effect on the transitions to old-age pension programs (ER), since those who are no 


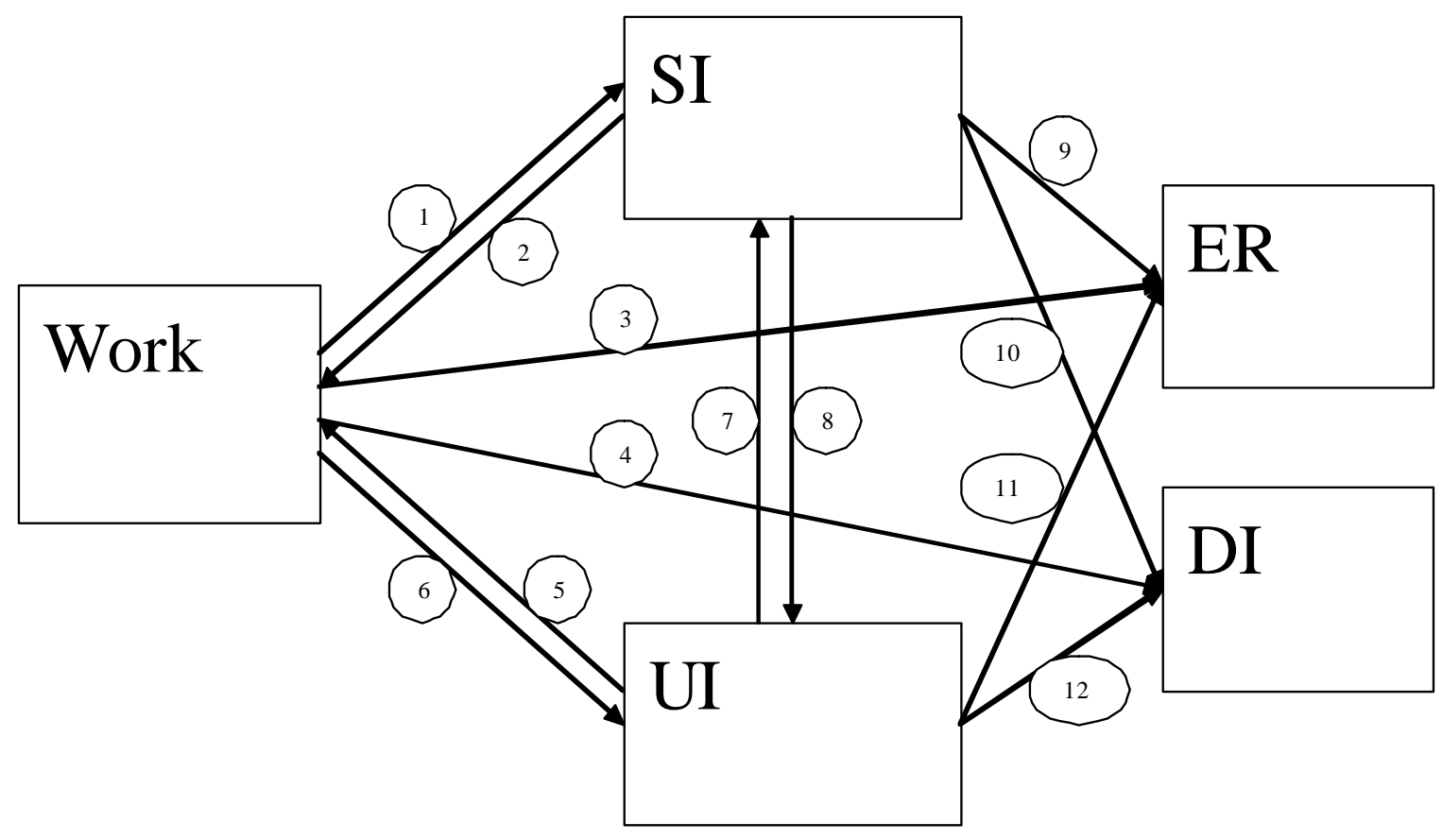

Figure 3: Transitions between gainful employment and UI, SI, DI and ER. 
longer eligible for DI in the post-reform regime may claim benefits from the old-age pension program.

\section{Data}

We use data from the LISA panel. This data set contains information on all individuals permanently living in Sweden. The information in LISA is obtained from two main sources:

- The income and wealth register (Inkomst- och förmögenhetsstatistiken, IoF/IoT). This register consists of tax return data and information on separate income components from different parts of the income security system on all people registered as taxpayers in Sweden. We have data from this register between 1990 and 2002.

- The Enterprise and Workplace register compiled by Statistics Sweden. This register contains information on employer and workplace for all individuals permanently living in Sweden.

In addition to data from LISA, we use data from FAD (Företagens och arbetsställenas dynamik), which is a refined register produced by Statistics Sweden from the basic Enterprise and Workplace registers.

Throughout, we restrict our sample to male workers. We also restrict it to individuals older than age 40. The sample is classified into seven five-year age groups.

The detailed information on income components in our data is used to classify individuals into one of the seven states on basis of main income 
source, defined as more than 50 percent of non-capital income being obtained from this income source. For an individual to be classified as "Working" income from work must be greater than 100,000 SEK per year. ${ }^{3}$ The main income sources are: Working (Work), Disability Insurance (DI), Sickness Insurance (SI), Unemployment Insurance (UI), a combination of DI, SI and/or UI (Combined), Early Retirement (ER) and Others (Others). The "Others" category consists of students, individuals on parental leave and individuals with income from work below 100,000 SEK but with income from work as their dominating income source. In the separate analysis of displaced workers, we define a worker as displaced if the workplace assigned to the individual closes down in the first year in the two-year panel.

Transition probabilities are calculated for each pair of consecutive years during the period 1994 to 2002, for individuals who are in one of the seven states in both years. Descriptive statistics on the number of observations in each state for the entire period under study are shown in the Appendix.

\section{Empirical Strategy}

Our empirical strategy for evaluating the reform is based on the differencesin-differences methodology using the group aged 60 to 64 as the treatment group and those aged between 55 and 59 as the control group. There are three main underlying assumptions to our identification of the causal effect of the reform. First, a common time effect in the two groups. This means that if the reform did not take place, there would be parallel developments in the different transitions under study in the two groups. This, in turn,

\footnotetext{
${ }^{3} 1$ Euro is around 9 SEK and 1 US Dollar is around 7.20 SEK in 2006.
} 
implies that we would expect parallel developments both before and after the intervention. Second, no spill-over or general equilibrium effects of the reform. This means that the stricter eligibility rules for the treatment group should not indirectly affect any transitions of the control group. One could think of a situation where this would not hold if there was a substantial increase in the labor supply of older workers. To the extent that the younger workers in the control group are a complement or substitute to this group, it would affect labor demand for this group and be likely to have an effect on their unemployment rate. Third, exogeneity of the reform. This means that the reform did not just institutionalize a pre-existing trend in eligibility to DI for the treatment group, but had an independent effect. It also implies that the reform could not be anticipated by the insured workers so that they are able to change their behavior on basis of their expectations.

We use three different methods to estimate the effect of the reform on the transitions between different labor market states. In all three methods, we use two-year panels measuring the transitions between the different states defined in Figure 3. First, we use a traditional differences-in-differences model, i.e., the following regression model

$$
S_{i t}=X_{i t}^{\prime} \boldsymbol{\beta}+\lambda_{t}+\delta A G E 6064_{i t}+\gamma A G E 6064_{i t} * P O S T_{i t}+\varepsilon_{i t},
$$

where $S$ is an indicator variable equal to 1 if the individual takes the transition under study and equal to 0 otherwise; $X$ is a vector of personal characteristics including indicator variables for education and county of living; $\lambda$ is a vector of year fixed effects, $A G E 6064$ is a dummy variable for being in the age group affected by the 1997 policy change and POST is a dummy 
variable for the post reform period. The $\gamma$ parameter measures the effect of the policy change, i.e., the differential effect on the group affected by the policy change relative to the age group 55-59 used as the control group. We use OLS to estimate this model.

This approach for identifying the effect of a policy intervention has been criticized in several recent papers (see e.g. Bertrand et al., 2004, or Donald and Lang, 2004). In particular, the presence of group effects and autocorrelation causes problems in these models. The standard errors may be underestimated, which leads to misleading inference.

To deal with these problems, we apply the two-step method suggested by Wooldridge (2003). In the first step, we estimate group effects, i.e.,

$$
S_{i t}=X_{i t}^{\prime} \boldsymbol{\beta}+c_{g}+u_{i t}
$$

where $c_{g}$ is the set of group- and time-specific effects. In the second step, we regress these estimates on the AGE6064, POST and AGE6064*POST. Following Wooldridge (2003), we use the inverse of the estimated standard errors for the group effects as weights to obtain efficient estimates.

To make the analysis more transparent and to investigate to what extent the assumption of parallel trends of the control and treatment groups holds before and after the intervention, we also show graphs of the differencesin-differences for the transition probabilities. Once more departing from two-year panels, we estimate transition probabilities as

$$
p_{\text {State }, t+1+1, \text { Age group }}=\frac{N_{\text {State }, t+1}}{N_{\text {Risk }, t}},
$$

where $N_{\text {State,t+1 }}$ is the number of individuals in the state under study in the second year and $N_{R i s k, t}$ is the number of individuals at risk in the first year. 
To show the effect of the reform of the Disability Insurance program, we use different age groups as control groups. We use the transition between 1994 and 1995 as the reference year. The reason for using these years as a reference is that the reform was announced in 1995 and there is a well-known anticipation effect from any reform of this kind. That is, as an example, the reform effect for the transition between the years 1998 and 1999 is calculated as

$$
\widehat{\gamma}_{98 / 99}=\left(\widehat{p}_{98 / 99,60-64}-\widehat{p}_{94 / 95,60-64}\right)-\left(\widehat{p}_{98 / 99,55-59}-\widehat{p}_{94 / 95,55-59}\right),
$$

where $\widehat{p}$ are the estimated transition probabilities by year and the different age groups. These graphs also serves as a refutability test, i.e. they show to what extent the changes occurring at the date of the reform were unique in magnitude during the entire time period covered by our data.

\section{Results}

The results are presented in five subsections. In the first, we estimate the direct effect of the reform on the share of workers on the Disability Insurance program. This can be interpreted as the gross effect of the reform not considering the possible counteracting of increased utilization of other social insurance programs. In the second subsection, we estimate the effect of the reform on employment, i.e. the net effect considering all possible sources of "crowding out" of the direct effect of Disability Insurance award rates on the other social insurance schemes. The last three subsections analyze the indirect effects on the unemployment rate, the share of workers on sickpay insurance and early retirement schemes, respectively. 


\subsection{Effects on DI take up}

The flows from DI back to employment or other programs are very small in the age groups considered. Therefore, the effect on disability take-up is determined by the effect on the inflow into DI. The upper panel in Table 1 shows three sets of results for total inflow to DI from all other states. First, it shows conventional differences-in-differences results for the entire population from two-year panels using 1994/95 as a "base year" for the years 1995/96 to 1998/99. The age group 60-64 is used as the "treated" group and those aged 55-59 as the control group. Second, it shows the corresponding estimates for the sub-set of displaced workers. Finally, it shows the results from the two-stage estimator described in Section 4.

For the two-stage estimator, we use the transitions 1994/95 and 1995/96, excluding the "anticipation effects" in the transition between the years 1996 and 1997, as the pre-reform period and the transitions 1997/98 through 2001/02 as the post-reform period. This means that we only use 7 observations in the regressions in the second stage and we cannot use the asymptotic critical values in deciding statistical significance. Therefore, we have marked statistical significance using the convention * for significance at the 10 percent level, ${ }^{* *}$ for the 5 percent level and ${ }^{* * *}$ for the 1 percent level for the relevant number of degrees of freedom.

As can be seen from the upper panel in Table 1 the overall effect for male workers on the transition to DI is around 0.5 percent of the entire male population in the 60-64 age group. However, the effects are not statistically significant using the more robust two-stage estimator. It can also be seen that the result is not primarily attributed to displaced workers. The effect 


\begin{tabular}{|c|c|c|c|c|c|c|c|c|c|}
\hline & \multicolumn{2}{|c|}{ All workers } & \multicolumn{6}{|c|}{ Displaced Workers } & \multirow{3}{*}{$\begin{array}{c}\text { All workers } \\
\text { Two-step } \\
\text { Estimates }\end{array}$} \\
\hline & 1995 & 1996 & 1997 & 1998 & 1995 & 1996 & 1997 & 1998 & \\
\hline & & & & & & & & & \\
\hline \multicolumn{10}{|c|}{ Transition to DI } \\
\hline \multirow[t]{2}{*}{ All states $\longrightarrow$ DI } & 0.0000 & 0.0176 & -0.0056 & -0.0048 & 0.0012 & 0.0219 & -0.0038 & -0.0019 & -0.0104 \\
\hline & $(0.0006)$ & $(0.0006)$ & $(0.0006)$ & $(0.0005)$ & $(0.0038)$ & $(0.0041)$ & $(0.0033)$ & $(0.0040)$ & $(0.0056)$ \\
\hline \multicolumn{10}{|c|}{ Effects on Employment } \\
\hline Employment $\longrightarrow$ & -0.0209 & 0.0083 & -0.0009 & -0.0070 & - & - & - & - & -0.0074 \\
\hline Non-employment & $(0.0015)$ & $(0.0014)$ & $(0.0015)$ & $(0.0014)$ & & & & & $(0.0116)$ \\
\hline Non-employment $\longrightarrow$ & -0.0055 & -0.0228 & 0.0070 & 0.0129 & -0.0007 & -0.0140 & 0.0121 & 0.0189 & $0.0100^{* *}$ \\
\hline Non-employment & $(0.0014)$ & $(0.0014)$ & $(0.0013)$ & $(0.0013)$ & $(0.0140)$ & $(0.0138)$ & $(0.0145)$ & $(0.0150)$ & $(0.0036)$ \\
\hline
\end{tabular}

Table 1: Point estimates of the differences-in-differences results of the effect of the DI reform on different transitions on the labor market. Standard errors in parentheses.

in this group is in general smaller and insignificant.

The apparent "spike" in the transition to DI in 1996 is due to the fact that the new eligibility rules were announced more than two years before they were implemented. That is, workers who believed they would pass the pre-reform eligibility rules, but not the post-reform ones, applied under the pre-reform regime. This anticipation effect corresponds to almost 2 percent of the labor force in the age group and clearly violates the assumption of exogeneity of the reform, since it is likely to affect the composition of the population at risk when the transition to DI is estimated for the years after the reform. The estimate of the effect of the reform is therefore likely to have an upward bias.

Figure 4 shows the results graphically. ${ }^{4}$ The upper panel of Figure 4

\footnotetext{
${ }^{4}$ Since the entire population is included in the data underlying the estimates shown
} 
shows the transition probabilities into DI from all other states by age group and the lower panel the differences-in-differences in the transition probabilities between the affected age group and each of the other groups using 1994 as the base year. The most apparent result shown in Figure 4 is the "spike" following the anticipation of the reform, discussed in the previous paragraph. It can also be seen that the transition rate to DI in the affected group decreases relative to all other comparison groups, although the magnitude of the effect is smallest vis-à-vis the group closest in age to the affected group, the one aged 55-59. This group also shows a parallel trend in the transition rate to the affected group before the reform.

in the figures, it should be noted that any imprecision in these estimates could not be attributed to sampling errors. However, for considerations on measuring the effect of the reform, see the discussion in Section 5. 


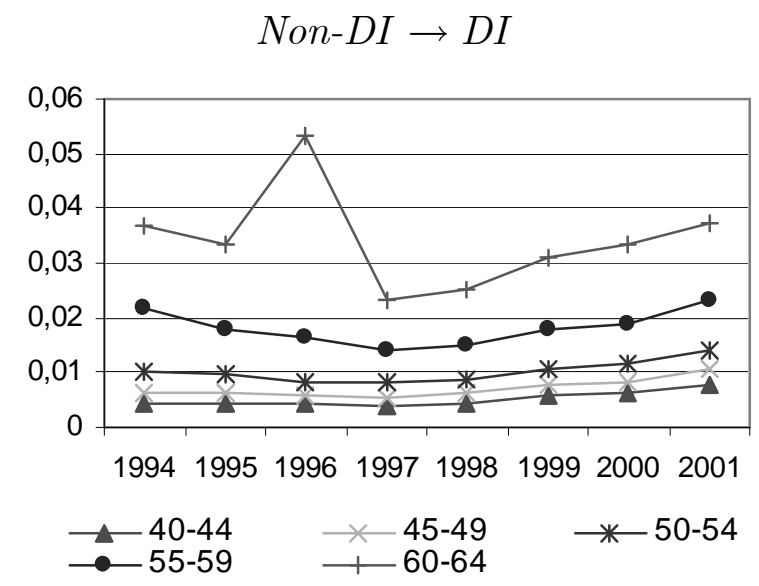

Non-DI $\rightarrow$ DI: Difference-in-Differences

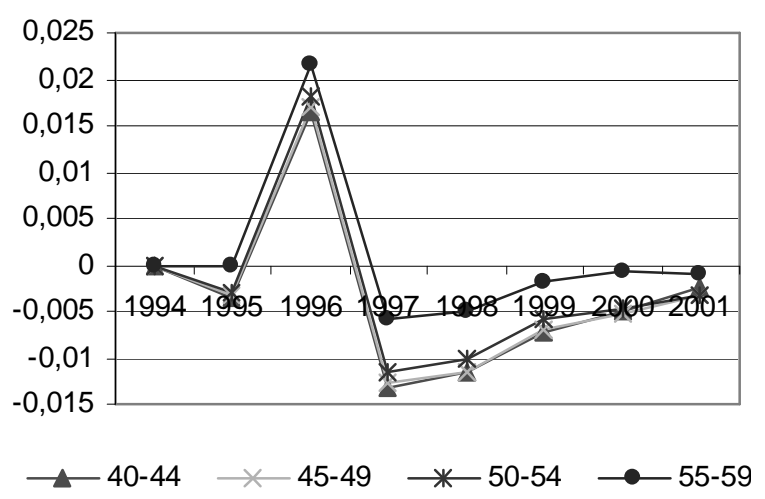

Figure 4. Upper panel: transition to DI from all other states by age group. Lower panel: differences-in-differences estimates for the age group 60-64 relative to all other age groups using 1994 as the base year.

\subsection{Effects on Employment}

The overall effect of the reform on employment can be divided into effects on transition out of employment to all other states and transitions into employment from all other states - or its complement, the persistence of nonemployment. The lower panel of Table 1 shows the estimates of the changes in the transitions out of the labor force and persistence in the non-employment 
states. The results on the transition out of employment show a very erratic pattern. This can be interpreted as an effect of dominating group effects and is also reflected in the large standard errors for the two-step estimator, which do not give any significant result. This means that we maintain the hypothesis of no effect on the transition out of employment of the reform.

The left panel of Figure 5 shows the overall effect on the transition out of employment. The spike from the anticipation of the 1997 reform can also be seen for this transition. As opposed to the effect on the transition to DI, there is no apparent effect on the transition from employment during the years 1997 to 1999. During the years 2000 and 2001, there is a comparatively large decrease in the exit rate from employment in the 60-64 age group as compared to the other groups. The results in Figure 5 confirm the difficulties in making any conclusive inference on the effect of the 1997 reform on transition out of employment, as discussed above.

The right panel of Figure 5 shows the overall persistence in non-employment. It is not possible to detect any effect of the reform. If anything, the persistence in non-employment of the affected group increases relative to that in the 55-59 age group. This is reflected in the significantly positive estimate from the two-step estimator shown in Table 1. Thus, any expected effect of faster return to employment from the reform did not happen. 
Employment $\rightarrow$ Non-Employment

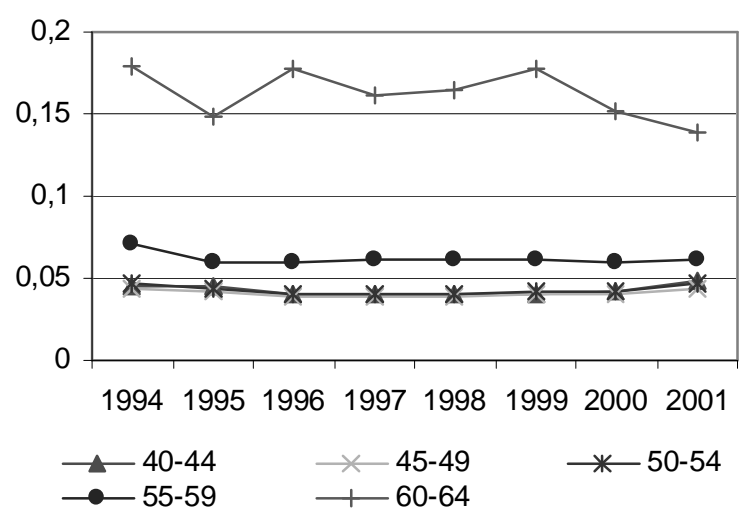

Employment $\rightarrow$ Non-Employment: Difference-in-differences

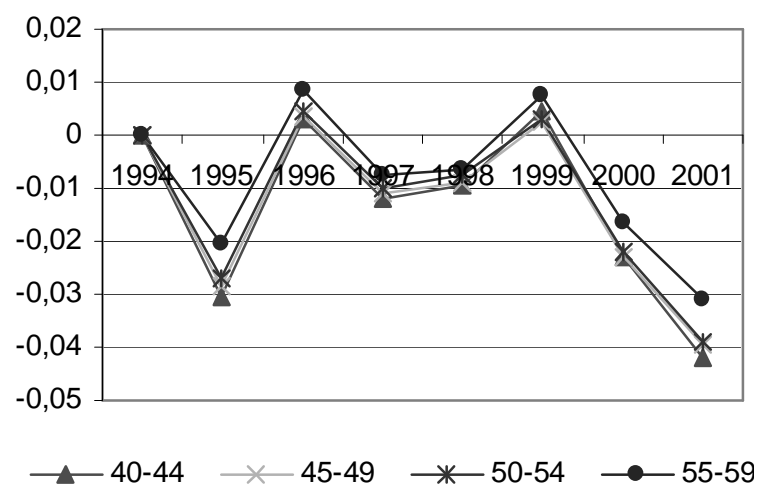

Non-Employment $\rightarrow$ Non-Employment

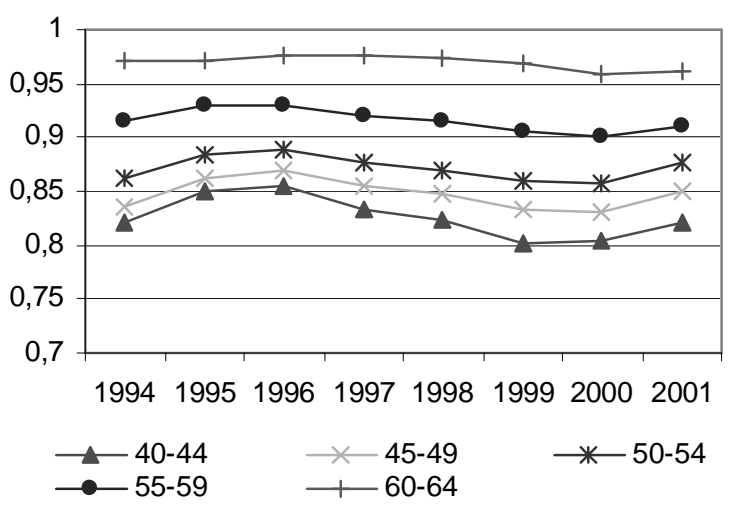

Non-Employment $\rightarrow$ Non-Employment: Difference-in-differences

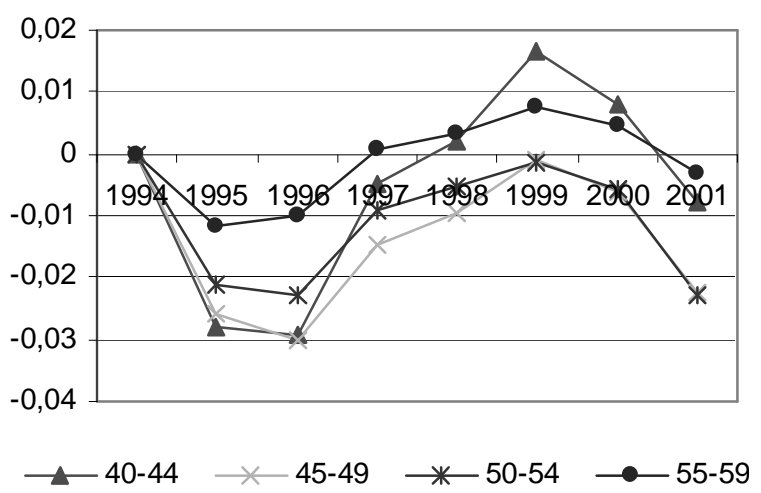

Figure 5. Upper panels: transitions from all employment to all non-employment states and from all non-employment to all non-employment states by age group. Lower panels: differences-in-differences estimates for the age group 60-64 relative to all other age groups using 1994 as the base year.

\subsection{Effect on Unemployment}

As explained in Section 3, the 1997 reform may potentially have an effect on both the inflow to and the persistence in the unemployment state. Figure 6 summarizes our results on these effects. The upper left panel shows the 
transition probabilities from Employment to Unemployment for different age groups; the upper right panel shows the corresponding transition probabilities from Unemployment to DI; the lower right panel shows the persistence probabilities in the Unemployment state; finally, the lower right panel shows the development of transition probabilities from Unemployment back to Employment.
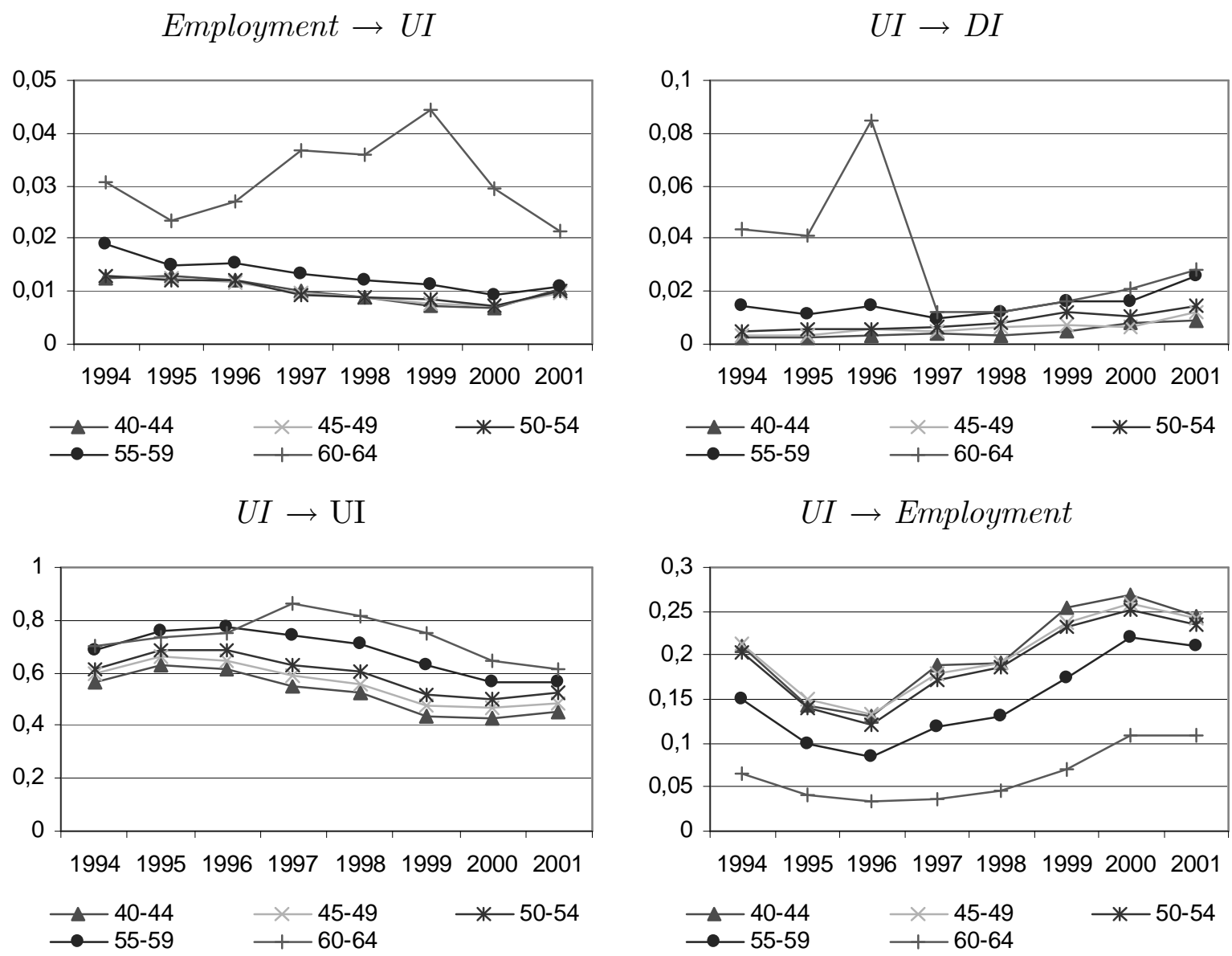

Figure 6. Transitions between different states and unemployment by age group.

Table 2 summarizes the results on the effect of the 1997 reform on Unemployment by giving the point estimates for the effect of the reform on 


\begin{tabular}{lc}
\hline \hline & \\
Employment $\rightarrow$ UI & $0.0104^{*}$ \\
& $(0.0049)$ \\
$\mathrm{UI} \rightarrow \mathrm{DI}$ & $-0.0387^{* * *}$ \\
& $(0.0093)$ \\
$\mathrm{UI} \rightarrow \mathrm{UI}$ & $0.1022^{* * *}$ \\
& $(0.0269)$ \\
$\mathrm{UI} \rightarrow$ Employment & $-0.0306^{* *}$ \\
& $(0.0118)$ \\
\hline
\end{tabular}

Table 2: Two-stage estimates of the effect of the reform of eligibility for DI on utilization of UI. Pairwise transitions between 1994 and 2002 included in the estimates. Anticipation transitions between 1996 and 1997 excluded. *** significant at the 1 percent level; ${ }^{* *}$ significant at the 5 percent level; * significant at the 10 percent level.

different transitions from the two-step estimator.

The inflow into the Unemployment state may be affected by the reform since the pre-reform eligibility rules provided an exit route from the labor force for workers who had to give up their current job for health reasons, or for workers who left their employment for other reasons. As can be seen in the upper left panel of Figure 6, there is an apparent increase in the transition probabilities in the year of the reform. Since this change could only be seen in the age group affected by the reform, it is likely to be attributed to the policy change. However, the change was reverted to the pre-reform level in the years 2000 and 2001. These partly counteracting effects are also reflected in the point estimate of the overall effect on this transition probability that is only marginally significant.

The change in the persistence of the rate of non-employed workers contains three main elements. First, the upper right panel shows there to be an 
unambiguous direct effect of the reform on the transition from Unemployment to DI: there is a clear decrease in the transition to DI following the 1997 reform. As opposed to the effect on transition from employment, this effect persists over the entire period under study. Table 2 shows this reform effect to be highly significant. Finally, there is an apparent anticipation effect in 1996, where the transition from Unemployment to DI almost doubled.

Second, the lower left panel in Figure 6, showing the estimates of the persistence in the unemployment state, reveals that the first direct effect also translates into an overall increase in the persistence in unemployment. Once more, Table 2 shows this effect to be highly significant. Third, the lower right panel shows the change in the probability of moving from unemployment to employment. Although it can be seen that there is a development towards increased transition back to employment in the affected group, the increase is faster in the other groups. This means that the intended effect of a faster transition back to employment, when the chances of being eligible for DI were altered, did not occur.

\subsection{Effects on the Share of Workers on Sickpay Insur- ance}

For the same reasons that the 1997 reform has an effect on the inflow and persistence in unemployment, it is likely to have a corresponding effect on the utilization of the sickpay insurance, i.e. the social insurance program replacing forgone earnings due to temporary lost ability to work. The upper left panel in Figure 7 shows the development of probability of transition from employment to the sickpay insurance program. There was a rapid increase 
in the transition to this program in all age groups starting in 1997. However, the probability of transition increased much faster in the age group affected by the reform. The difference in transition probabilities decreases towards the end of the period under study.

\section{Employment $\rightarrow$ SI}

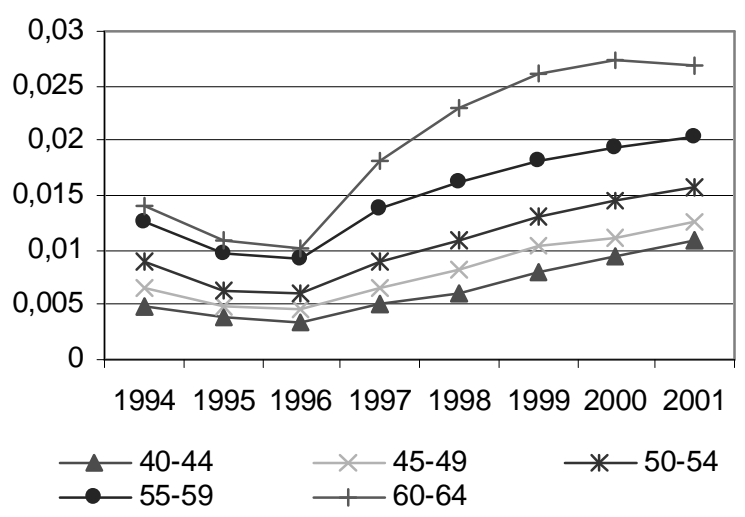

$$
S I \rightarrow S I
$$

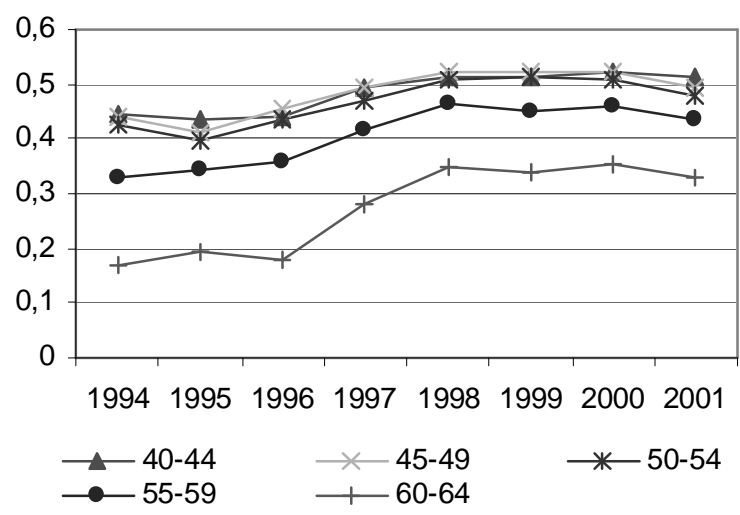

$S I \rightarrow D I$

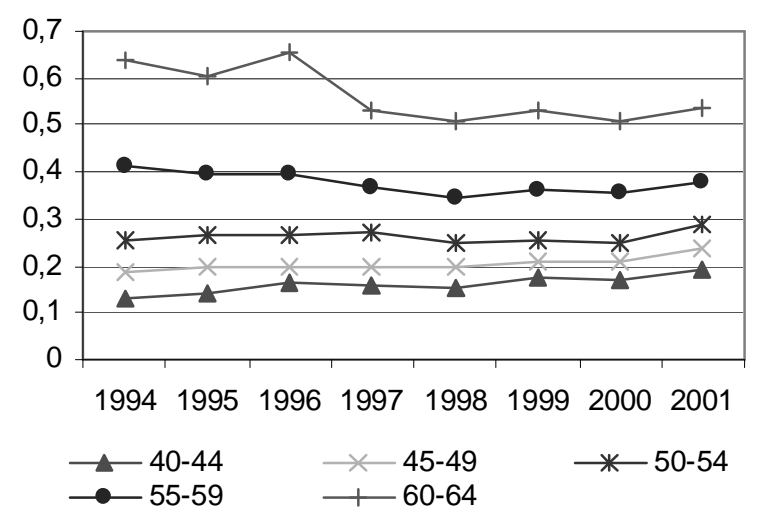

$S I \rightarrow$ Employment

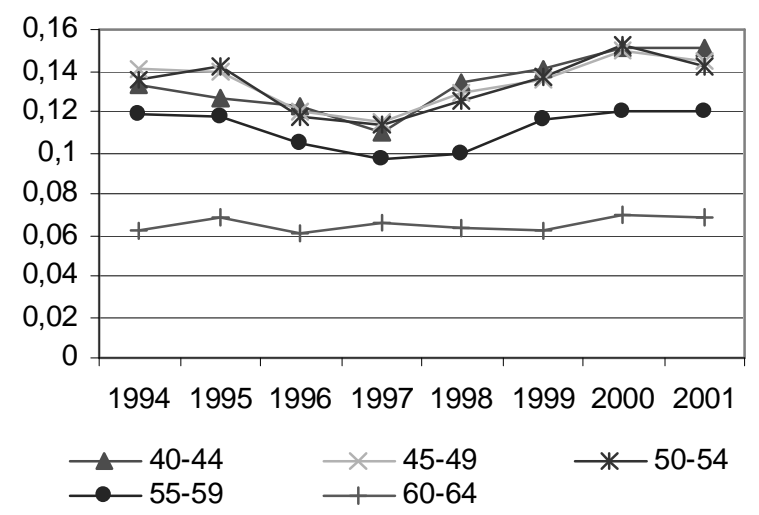

Figure 7. Transitions between different states and sickpay insurance by age group. The upper right panel in Figure 7 shows the development in the transition probabilities from the sickpay insurance program to DI. The graph for the 60-64 age group shows a marked 0.1 decrease in this probability in 1997. There is also a slight decrease in this transition for the age group 55-59, making the decrease as compared to this control group somewhat smaller. 
However, it is very likely that this change can be attributed to the reform, since it happened all at once in 1997 and has been constant ever since.

The lower left hand panel shows changes in the persistence in the sickpay insurance program. It can be seen that the persistence increases in all age groups, but more in the oldest age group after the reform. Finally, the lower right panel shows to what extent the decrease in the transition from the sickpay insurance program to DI really led to an increased transition back to employment from this program. The rapid decrease in these transitions compared to all control groups in 1997 can be interpreted as an effect of the reform. However, the results also show that there was a rapid reversion in the transition probabilities as compared to all groups by the end of the period under study, implying that the effect was only transitory.

Table 3 summarizes the results on the effects on the sickpay insurance program and highlights three significant effects of the reform: the higher transition from employment to the sickpay insurance program, the decreased transition from the sickpay insurance to DI and the increased persistence in SI. Finally, the results show that the decreased transition to DI did not translate into a significant increase of transitions back to employment, taking all post reform transitions into account.

\subsection{Effects on Transition to Early Retirement}

A possible background for the small effect of the reform on transition to nonemployment is an increased transition to early retirement (old-age pension programs) in the group aged 60 to 64 . Figure 8 empirically examines this hypothesis by showing the development of the transition to early retirement 


\begin{tabular}{lc}
\hline \hline & \\
Employment $\rightarrow$ SI & $0.0104^{*}$ \\
& $(0.0049)$ \\
$\mathrm{SI} \rightarrow \mathrm{DI}$ & $-0.0578^{* * *}$ \\
& $(0.0098)$ \\
$\mathrm{SI} \rightarrow \mathrm{SI}$ & $0.0453^{* * *}$ \\
& $(0.0091)$ \\
$\mathrm{SI} \rightarrow$ Employment & -0.0025 \\
& $(0.0068)$ \\
\hline
\end{tabular}

Table 3: Two-stage estimates of the effect of the reform of eligibility for DI on utilization of SI. Pairwise transitions between 1994 and 2002 included in the estimates. Anticipation transitions between 1996 and 1997 excluded. *** significant at the 1 percent level; ${ }^{* *}$ significant at the 5 percent level; ${ }^{*}$ significant at the 10 percent level.

in the different age groups.

The results do not support the hypothesis that stricter rules for DI eligibility led to an increase in the utilization of ER as an exit route. There are very small changes in the transition to these programs up to 1999. By the end of the period, there is a marked decline by about one percentage point in the transition to the early retirement programs.

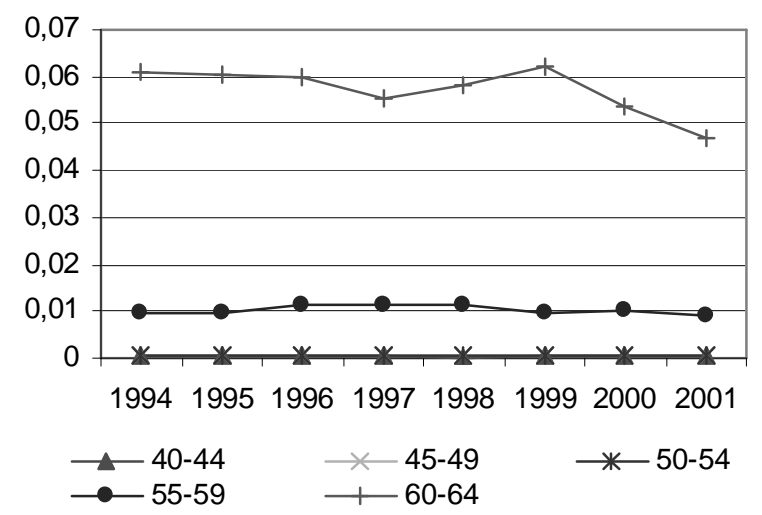

Figure 8. Transition to ER from all other states by age group. 


\section{Conclusions}

Did the 1997 abolition of the special eligibility rules for the age group 60-64 in Sweden's Disability Insurance program lead to the intended increase in employment in this age group? In this study, we find no empirical support for this being the case, at least not up to two or three years after the reform. Instead, we find that the different labor market insurance programs worked like communicating vessels in absorbing workers who did not qualify for DI under the post-reform eligibility rules. We find that both the unemployment rate and the utilization of the sickpay insurance system increased in the affected age group as a result of the reform. Going back to Figure 1 and 2 in the Introduction, our results suggest that the main part of the increase in the labor force participation rate among older workers starting by the end of the 1990ties, corresponded to an increased unemployment rate or an utilization of the sickpay insurance program, rather than an increased employment rate.

However, it could be argued that it takes more than two or three years for potentially positive effects on employment to appear, since the alternative labor market insurance programs are "absorbing states" to a lesser extent than DI and it takes time for employees, employers and labor unions to adjust to the post-reform rules. We find some support for such reasoning in our results. By the end of the period under study, we find a decreased transition out of employment in the affected age group, as well as a reduced persistence in the combined Non-employment states, including Unemployment.

The empirical result obtained in this study also reveals a very large anticipation effect of the reform in a radically increased transition to the DI 
program the year before the reform was implemented. This increase corresponds to two percent of the work force in the affected age group. It is not likely that such a large effect was solely initiated by the insured workers, but rather, as indicated by anecdotal evidence, also by the social security administration itself.

\section{References}

Autor, D.H. and Duggan, M.G. (2003) "The Rise in the Disability Rolls and the Decline in Unemployment", Quarterly Journal of Economics, 118, $157-205$.

Bertrand, M., E. Duflo and S. Mullainathan (2004) "How Much Should We Trust Difference in Difference Estimates", Quarterly Journal of Economics, 119 (1), 249-275.

Donald, S. and K. Lang (2001) "Inference with Difference in Differences and Other Panel Data" Working Paper, University of Texas.

Campolieti, M. (2002) "Disability and Labour Force Participation of Older Men in Canada", Labour Economics, 9, 405-432.

Campolieti, M. (2003) "Disability insurance eligibility criteria and the labor supply of older men", Economics Bulletin, 10, 1-7.

Eklöf, M. and D. Hallberg (2004) "Private Alternatives and Early Retirement Programs", Working Paper 2004:5, Department of Economics, Uppsala University.

Gruber, J. (2000) "Disability Insurance Benefits and Labor Supply", Journal of Political Economy, 108, 1162-1183.

Palme, M. and I. Svensson (1999) "Social Security, Occupational Pensions and Retirement in Sweden". In Jonathan Gruber and David Wise (eds.) "So- 
cial Security and Retirement around the World", 1999, Chicago University Press: Chicago.

Palme, M. and I. Svensson (2004) "Income Security Programs and Retirement in Sweden". In Jonathan Gruber and David Wise (eds.) "Social Security and Retirement Around the World: Micro-estimates", 2004, Chicago University Press: Chicago.

Wadensjö, E. (2003) “Arbetslöshetsförsäkring, sjukförsäkring, förtidspension - kommunicerande kärl?". In Birgitta Swedenborg (ed.) Varför är svenskarna så sjuka?. SNS Förlag: Stockholm.

Wooldridge, J. (2003) "Cluster-Sample Methods in Applied Econometrics" The American Economic Review 93(2), 133-138. 


\section{Appendix: Descriptive Statistics}

\begin{tabular}{lcccccccc}
\hline \hline \multicolumn{2}{c}{ Work } & DI & SI & UI & Comb & ER & Others & All states \\
Aged & $55-59$ & & & & & & & \\
1994 & 282,722 & 78,126 & 9,814 & 20,497 & 16,870 & 4,864 & 44,043 & 456,936 \\
1995 & 295,992 & 78,661 & 9,728 & 22,212 & 15,161 & 5,381 & 42,670 & 469,805 \\
1996 & 319,903 & 79,196 & 8,398 & 24,965 & 13,174 & 5,851 & 41,065 & 492,552 \\
1997 & 345,389 & 80,351 & 8,449 & 27,811 & 11,231 & 6,209 & 41,887 & 521,327 \\
1998 & 373,133 & 81,227 & 11,888 & 27,736 & 10,959 & 6,881 & 42,543 & 554,367 \\
1999 & 402,123 & 84,726 & 16,046 & 26,218 & 10,636 & 7,993 & 42,246 & 589,988 \\
2000 & 427,376 & 90,534 & 20,751 & 22,389 & 10,438 & 8,376 & 42,168 & 622,032 \\
2001 & 442,461 & 96,758 & 24,082 & 17,955 & 9,386 & 8,469 & 40,954 & 640,065 \\
& & & & & & & & \\
Aged & $60-64$ & & & & & & & \\
1994 & 151,977 & 121,750 & 5,832 & 18,215 & 21,025 & 41,993 & 39,493 & 400,285 \\
1995 & 159,916 & 118,023 & 5,765 & 20,056 & 17,960 & 42,737 & 37,910 & 402,367 \\
1996 & 172,932 & 115,095 & 4,814 & 21,495 & 12,902 & 43,538 & 35,464 & 406,240 \\
1997 & 180,540 & 118,713 & 4,447 & 23,994 & 8,977 & 46,811 & 33,549 & 417,031 \\
1998 & 189,961 & 115,234 & 7,043 & 29,267 & 8,277 & 49,274 & 31,597 & 430,653 \\
1999 & 199,273 & 112,864 & 10,449 & 30,647 & 7,942 & 50,188 & 30,252 & 441,615 \\
2000 & 207,782 & 114,041 & 13,412 & 29,804 & 7,837 & 51,773 & 29,510 & 454,159 \\
2001 & 231,021 & 118,765 & 16,452 & 22,865 & 7,521 & 47,558 & 32,546 & 476,728 \\
\hline
\end{tabular}

Table 4: The number of individuals by state. 55-59 and 60-64 year olds. 